\title{
System Characterization Report on Planet SkySat
}

Chapter E of

System Characterization of Earth Observation Sensors

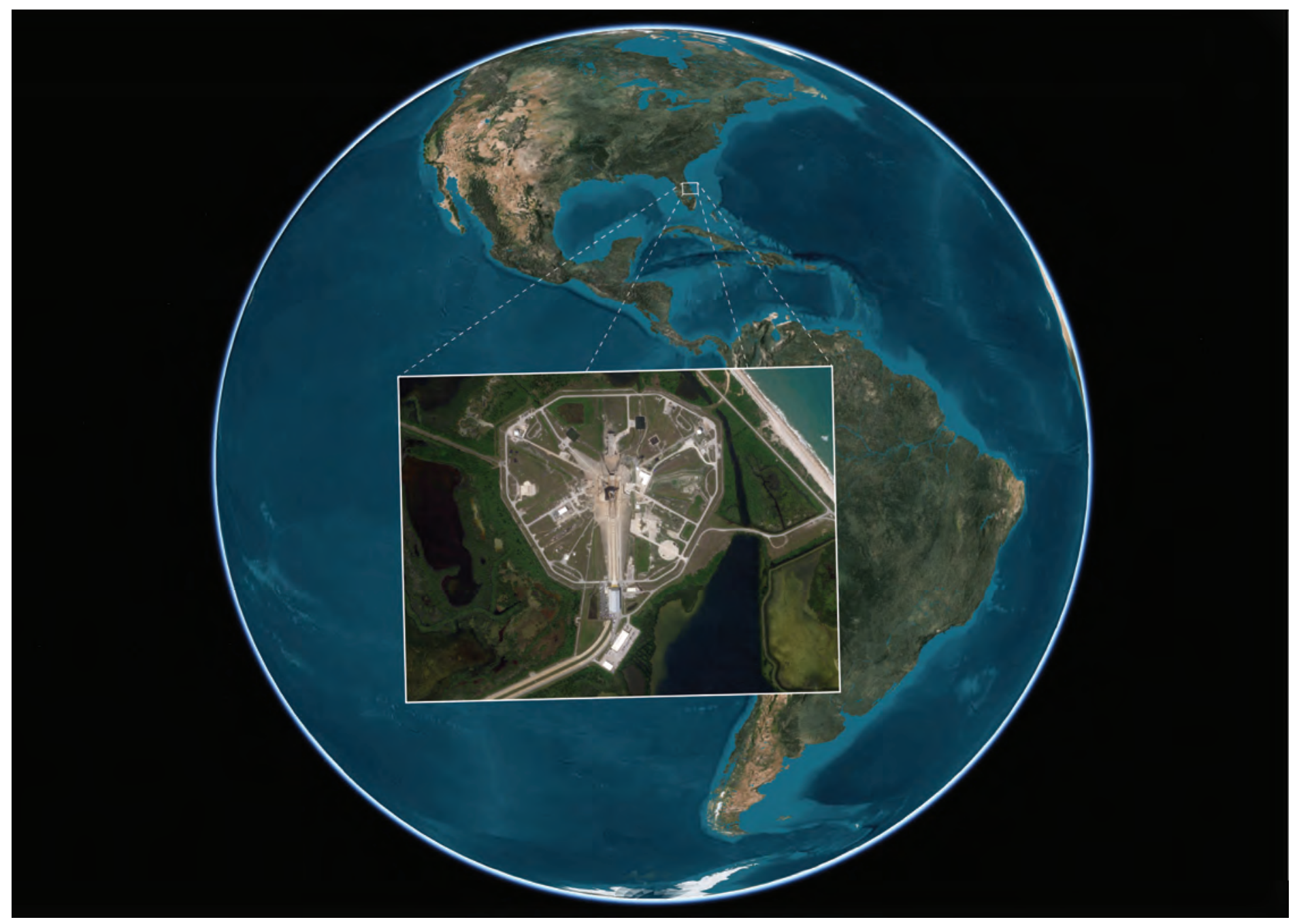

Open-File Report 2021-1030-E

U.S. Department of the Interior U.S. Geological Survey 
Cover: Satellite image showing SpaceX's Falcon 9 rocket preparing to launch into orbit from Cape Canaveral, Florida, taken on May 29, 2020, using the Planet SkySat sensor. Image courtesy of Planet, licensed under the Creative Commons Attribution-NonCommercial 2.0 Generic license. Image of Earth from Analytical Graphics, Inc., Systems Tool Kit. 


\section{System Characterization Report on Planet SkySat}

By Minsu Kim, ${ }^{1}$ Seonkyung Park, ${ }^{1}$ Aparajithan Sampath, ${ }^{1}$ Cody Anderson, ${ }^{2}$ and Gregory L. Stensaas ${ }^{2}$

Chapter E of System Characterization of Earth Observation Sensors

Compiled by Shankar N. Ramaseri Chandra ${ }^{1}$

${ }^{1}$ KBR, Inc., under contract to the U.S. Geological Survey.

${ }^{2}$ U.S. Geological Survey.

Open-File Report 2021-1030-E 


\section{U.S. Geological Survey, Reston, Virginia: 2022}

For more information on the USGS - the Federal source for science about the Earth, its natural and living resources, natural hazards, and the environment—visit https://www.usgs.gov or call 1-888-ASK-USGS.

For an overview of USGS information products, including maps, imagery, and publications, visit https://store.usgs.gov/.

Any use of trade, firm, or product names is for descriptive purposes only and does not imply endorsement by the U.S. Government.

Although this information product, for the most part, is in the public domain, it also may contain copyrighted materials as noted in the text. Permission to reproduce copyrighted items must be secured from the copyright owner.

Suggested citation:

Kim, M., Park, S., Sampath, A., Anderson, C., and Stensaas, G.L., 2022, System characterization report on Planet SkySat, chap. E of Ramaseri Chandra, S.N., comp., System characterization of Earth observation sensors: U.S. Geological Survey Open-File Report 2021-1030, 17 p., https://doi.org/10.3133/ofr20211030E.

ISSN 2331-1258 (online) 


\section{Contents}

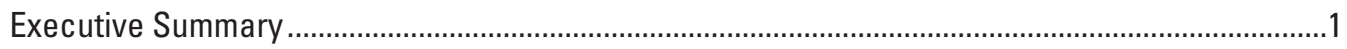

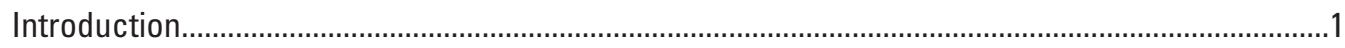

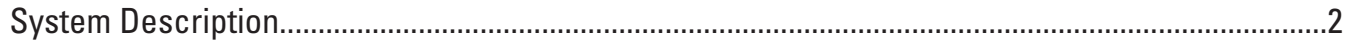

Satellite and Operational Details .......................................................................................

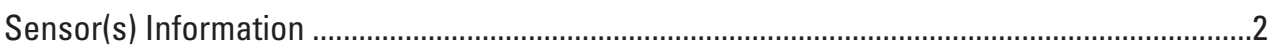

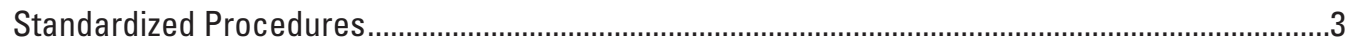

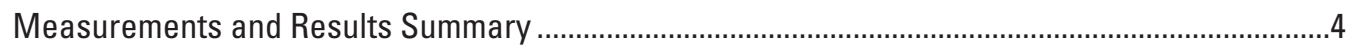

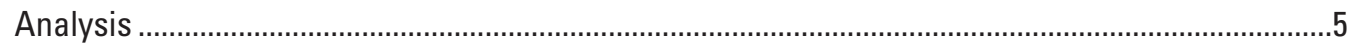

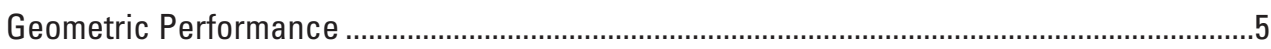

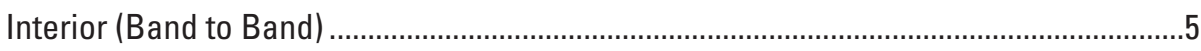

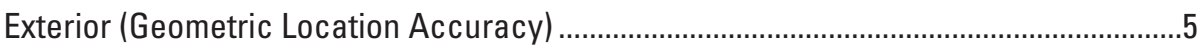

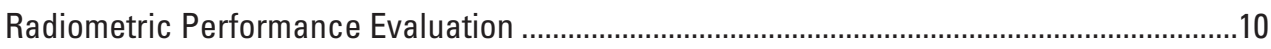

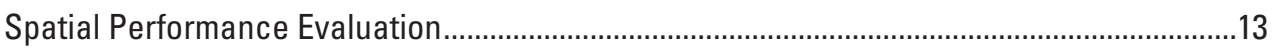

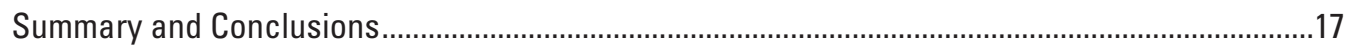

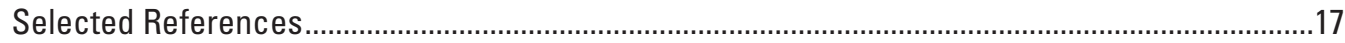

\section{Figures}

1. Graph showing Planet's SkySat relative spectral response ................................................

2. Graph showing band 1 to band 2 band-to-band results.................................................

3. Graph showing band 1 to band 3 band-to-band results ...................................................

4. Graph showing band 1 to band 4 band-to-band results .................................................

5. Geometric error for image compared to ground control points ........................................9

6. Graph showing Top of Atmosphere reflectance comparison for Sentinel-2 and Planet's SkySat band 1...............................................................................................10

7. Graph showing Top of Atmosphere reflectance comparison for Sentinel-2 and Planet's SkySat band 2.................................................................................................11

8. Graph showing Top of Atmosphere reflectance comparison for Sentinel-2 and Planet's SkySat band 3...........................................................................................

9. Graph showing Top of Atmosphere reflectance comparison for Sentinel-2 and

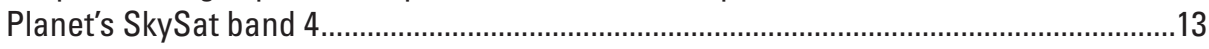

10. Image showing Planet's SkySat data over the Baotou, China, test site .........................14

11. Graphs showing band 1 edge spread and line spread function and full width at half maximum and modulation transfer function curves ...............................................15

12. Graphs showing band 2 edge spread and line spread function and full width at half maximum and modulation transfer function curves .................................................15

13. Graphs showing band 3 edge spread and line spread function and full width at half maximum and modulation transfer function curves ...............................................16

14. Graphs showing band 4 edge spread and line spread function and full width at half maximum and modulation transfer function curves 


\section{Tables}

1. Satellite and operational details for Planet's SkySat...........................................................2

2. Imaging sensor details for Planet's SkySat constellation......................................................

3. U.S. Geological Survey measurement results ...................................................................4

4. Band-to-band registration error for reference bands 1, 2, 3, and 4 ................................5

5. Geometric error relative to ground control points .............................................................8

6. Top of Atmosphere reflectance comparison against Sentinel-2 .....................................13

7. Spatial performance of Planet's SkySat .........................................................................14

\section{Conversion Factors}

U.S. customary units to International System of Units

\begin{tabular}{lll}
\hline Multiply & By & To obtain \\
\hline & Mass & \\
\hline pound, avoirdupois $(\mathrm{lb})$ & 0.4536 & kilogram $(\mathrm{kg})$ \\
\hline
\end{tabular}

International System of Units to U.S. customary units

\begin{tabular}{lcll}
\hline & Multiply & By & To obtain \\
\hline & Length & \\
\hline centimeter $(\mathrm{cm})$ & 0.3937 & inch (in.) \\
$\operatorname{meter}(\mathrm{m})$ & 3.281 & foot (ft) \\
$\operatorname{meter}(\mathrm{m})$ & 1.094 & yard (yd) \\
\hline
\end{tabular}

\section{Abbreviations}

ECCOE Earth Resources Observation and Science Cal/Val Center of Excellence

GCP ground control point

GSD ground sample distance

JACIE Joint Agency Commercial Imagery Evaluation

NIR near infrared

USGS U.S. Geological Survey 


\title{
System Characterization Report on Planet SkySat
}

\author{
By Minsu Kim, ${ }^{1}$ Seonkyung Park, ${ }^{1}$ Aparajithan Sampath, ${ }^{1}$ Cody Anderson, ${ }^{2}$ and Gregory L. Stensaas ${ }^{2}$
}

\section{Executive Summary}

This report addresses system characterization of Planet's SkySat and is part of a series of system characterization reports produced and delivered by the U.S. Geological Survey Earth Resources Observation and Science Cal/Val Center of Excellence. These reports present and detail the methodology and procedures for characterization; present technical and operational information about the specific sensing system being evaluated; and provide a summary of test measurements, data retention practices, data analysis results, and conclusions.

SkySat is a constellation of submeter resolution Earth observation satellites providing analytics services, highdefinition video, and imagery. The goal for the constellation is to capture multiple daily repeats of high-resolution imagery over any spot on the Earth. As of September 2020, 21 SkySat satellites have been launched, and the first launch occurred in November 2013. More information on Planet satellites and sensors is available in the " 2020 Joint Agency Commercial Imagery Evaluation-Remote Sensing Satellite Compendium" and from the manufacturer at https://www.planet.com/.

The Earth Resources Observation and Science Cal/Val Center of Excellence system characterization team completed data analyses to characterize the geometric (interior and exterior), radiometric, and spatial performances. Results of these analyses indicate that SkySat has an interior geometric performance in the range of a $0.38-(0.47$ pixel $)$ to 0.75 -meter ( $\mathrm{m}$; 0.93 pixel) root mean square error in easting and a 0.27 $(0.33$ pixel $)$ to $0.55-\mathrm{m}(0.68$ pixel $)$ root mean square error in northing, in band-to-band registration; an exterior geometric performance in the range of 0.26 ( 0.32 pixel) to $1.04 \mathrm{~m}$ (1.28 pixels) offset in comparison to ground control points; a radiometric performance in the range of 0.033 to 0.797 (linear regression); and a spatial performance in the range of 3.7 to 4.3 pixels at full width at half maximum, with a modulation transfer function at a Nyquist frequency in the range of 0.004 to 0.009 .

\section{Introduction}

Planet's SkySat satellites are high-resolution, multispectral microsatellites designed for high revisit, highresolution imaging. The first SkySat satellite was launched in November 2013. All SkySats collect imagery with submeter resolution, in the blue, green, red, and near-infrared (NIR) bands. All data are provided with permission from Planet through their standard data access portal.

The data analysis results provided within this report have been derived from approved Joint Agency Commercial Imagery Evaluation (JACIE) processes and procedures. JACIE was formed to leverage resources from several Federal agencies for the characterization of remote sensing data and to share those results across the remote sensing community. More information about JACIE is available at https://www.usgs.gov/ core-science-systems/eros/calval/jacie?qt-science_support_ page_related_con=3\#qt-science_support_page_related_con.

The purpose of this report is to describe the specific sensor or sensing system, test its performance in three categories, complete related data analyses to quantify these performances, and report the results in a standardized document. In this chapter, the SkySat sensor is described. The performance testing of the system is limited to geometric, radiometric, and spatial. The scope of the geometric assessment is limited to testing the interior alignments of spectral bands against each other, and the exterior alignment is tested in reference to photographidentifiable surveyed ground control points (GCPs).

The U.S. Geological Survey (USGS) Earth Resources Observation and Science Cal/Val Center of Excellence (ECCOE) project, and the associated system characterization process used for this assessment, follows the USGS Fundamental Science Practices, which include maintaining data, information, and documentation needed to reproduce and validate the scientific analysis documented in this report. Additional information and guidance about Fundamental Science Practices and related resource information of interest to the public are available at https/www.usgs.gov/about/organization/science-support/office-science-quality-and-integrity/fundamental-science-practices. For additional information related to the report, please contact ECCOE at eccoe@usgs.gov.

${ }^{1} \mathrm{KBR}$, Inc., under contract to the U.S. Geological Survey.

${ }^{2}$ U.S. Geological Survey. 


\section{System Description}

This section provides the nominal system characteristics that have a direct bearing on the imaging performance of the sensor. The nominal system characteristics include the satellite information (constellation, expected lifetime, and so on), operational details of the satellite (altitude, local imaging time, and so on), and the sensor characteristics (wavelength bands, ground sample distance [GSD], and so on). An understanding of these relevant system characteristics is useful and informs the parameters of analyses.

\section{Satellite and Operational Details}

Planet SkySat's nominal characteristics and the system's operational details most pertinent to the characterization process are provided in table 1 .

\section{Sensor(s) Information}

Planet's SkySat-12 specific imaging sensor details most pertinent to the characterization process are listed in table 2, and the relative spectral response curves are shown in figure 1.

Table 1. Satellite and operational details for Planet's SkySat.

[NIR, near infrared; lb, pound; km, kilometer; ${ }^{\circ}$, degree; min., minute; \pm , plus or minus; $\mathrm{m}$, meter; <, less than]

\begin{tabular}{|c|c|}
\hline Product information & SkySat data \\
\hline \multicolumn{2}{|c|}{ Satellite and operational information } \\
\hline Product name & Level 3B \\
\hline Satellite name & Planet SkySat \\
\hline Sensor name(s) & SkySat-12 \\
\hline Sensor type & Multispectral (blue, green, red, and NIR bands) \\
\hline Mission type & Global land-monitoring mission \\
\hline Launch date & Multiple dates, beginning November 2013 \\
\hline Launch vehicle & Minotaur-C \\
\hline Satellite weight & $220 \mathrm{lb}$ \\
\hline Number of satellites & 21 at time of testing \\
\hline Expected lifetime & About 6 years \\
\hline Operator & Planet \\
\hline \multicolumn{2}{|c|}{ Operational details } \\
\hline Operating orbit & Sun-synchronous orbit \\
\hline Orbital altitude range & $500 \mathrm{~km}$ \\
\hline Sensor angle altitude & $97.0^{\circ}$ inclination \\
\hline Orbit period & $94.6 \mathrm{~min}$. \\
\hline Imaging time & 13:00 (local solar time) \\
\hline Geographic coverage & Global \\
\hline Temporal resolution & Daily \\
\hline Temporal coverage & 2014 to present \\
\hline Imaging angles & $\pm 25^{\circ}$ \\
\hline Ground sample distance(s) & $0.81 \mathrm{~m}$ \\
\hline Data licensing & Restricted \\
\hline Data pricing & Limited free data; commercial imagery pricing \\
\hline Data latency & $<24$ hours \\
\hline Product abstract & https://www.planet.com/products/planet-imagery/ \\
\hline Product locator & https://www.planet.com/products/ \\
\hline
\end{tabular}


Table 2. Imaging sensor details for Planet's SkySat constellation.

[SkySat-12 has a swath width of 5.9 kilometers; nm, nanometer; m, meter; NIR, near infrared]

\begin{tabular}{lcccc}
\hline Spectral band(s) details & \multicolumn{4}{c}{ SkySat constellation } \\
\cline { 2 - 5 } & $\begin{array}{c}\text { Lower band } \\
(\mathbf{n m})\end{array}$ & $\begin{array}{c}\text { Upper band } \\
(\mathbf{n m})\end{array}$ & $\begin{array}{c}\text { Radiometric } \\
\text { resolution } \\
(\mathbf{b i t s})\end{array}$ & $\begin{array}{c}\text { Ground sample } \\
\text { distance } \\
(\mathbf{m})\end{array}$ \\
\hline Band 1-blue & 450 & 515 & 16 & 0.81 \\
Band 2-green & 515 & 595 & 16 & 0.81 \\
Band 3-red & 605 & 695 & 16 & 0.81 \\
Band 4-NIR & 740 & 900 & 16 & 0.81 \\
\hline
\end{tabular}

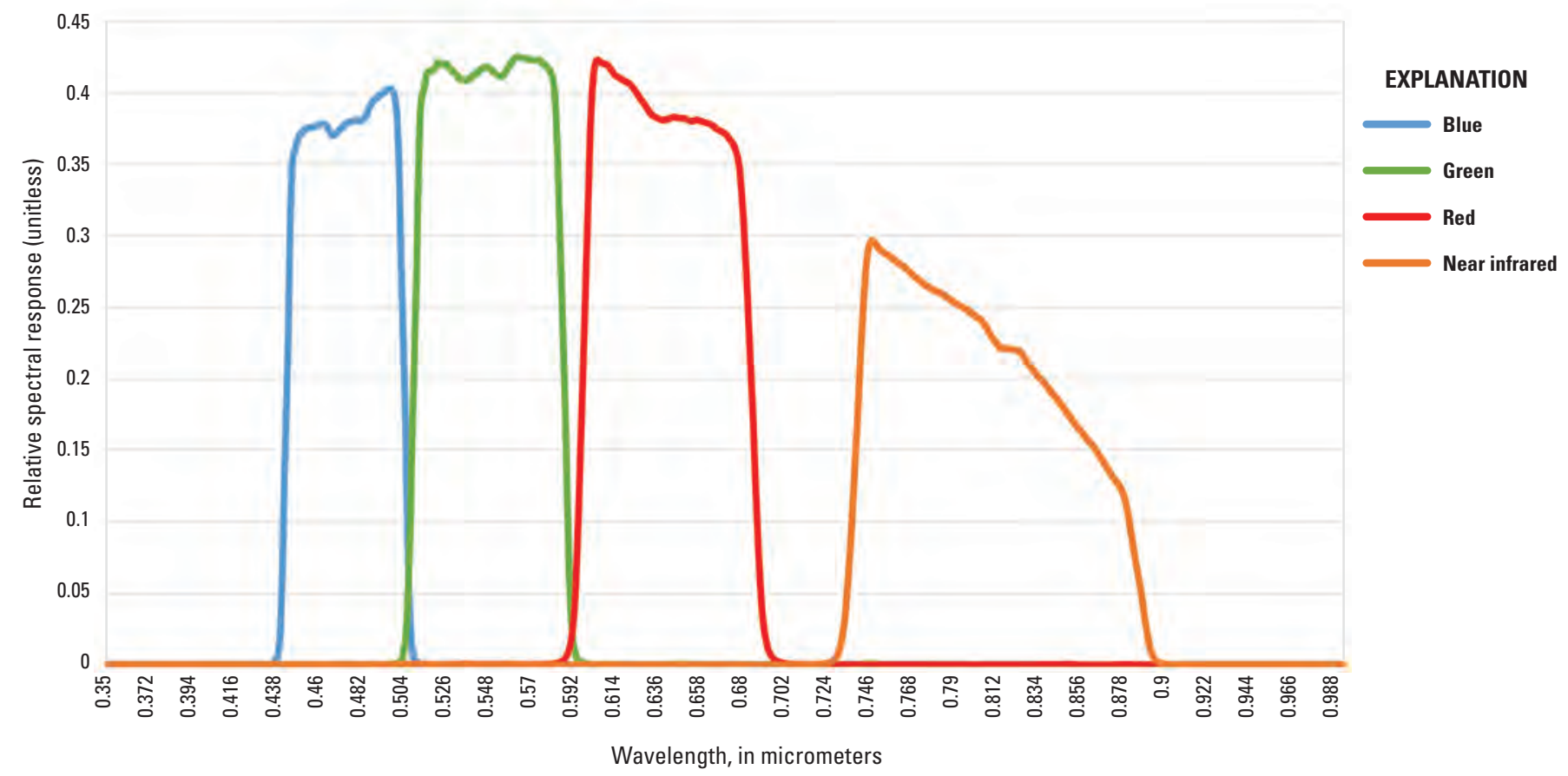

Figure 1. Planet's SkySat relative spectral response.

\section{Standardized Procedures}

ECCOE has established standard processes to identify Earth observing systems of interest and to assess the geometric, radiometric, and spatial qualities of data products from these systems.

The assessment steps are as follows:

- system identification and investigation to learn the general specifications of the satellite and its sensor(s);

- data receipt and initial inspection to understand the characteristics and any overt flaws in the data product so that it may be further analyzed;
- geometry characterization, including interior geometric orientation measuring the relative alignment of spectral bands and exterior geometric orientation measuring how well the georeferenced pixels within the image are aligned to a known reference;

- radiometry characterization, including assessing how well the data product correlates with a known reference and, when possible, assessing the signal-to-noise ratio; and

- spatial characterization, assessing the two-dimensional fidelity of the image pixels to their projected GSD.

Data analysis and test results are maintained at the USGS Earth Resources Observation and Science Center by the ECCOE project. 


\section{Measurements and Results Summary}

The observed USGS measurements are listed in table 3. Physical error, in meters, is calculated by the GSD $(0.81$ meter [m]) multiplied by the pixel error. Details about the methodologies used are outlined in the "Analysis" section.

Table 3. U.S. Geological Survey measurement results.

[USGS, U.S. Geological Survey; m, meter; RMSE, root mean square error; L8 OLI, Landsat 8 Operational Land Imager; FWHM, full width at half maximum; MTF, modulation transfer function; >, greater than]

\begin{tabular}{|c|c|}
\hline Description of product & Top of Atmosphere reflectance \\
\hline & USGS measurement results \\
\hline \multicolumn{2}{|c|}{ Geometric performance (easting, northing), in meters (pixels) } \\
\hline \multicolumn{2}{|r|}{ Radiometric performance (offset, slope) } \\
\hline $\begin{array}{l}\text { Radiometric evaluation (linear regression- } \\
\text { SkySat versus L8 OLI reflectance) }\end{array}$ & $\begin{array}{l}\text { Band } 1 \text { (offset, slope): } 0.056,0.644 \\
\text { Band } 2 \text { (offset, slope): } 0.033,0.754 \\
\text { Band } 3 \text { (offset, slope): } 0.052,0.797 \\
\text { Band } 4 \text { (offset, slope): } 0.113,0.670\end{array}$ \\
\hline \multicolumn{2}{|r|}{ Spatial performance } \\
\hline Spatial performance measurement & $\begin{array}{l}\text { Band 1: } F W H M=3.7 \text { pixels; } \text { MTF at Nyquist }=0.009 \\
\text { Band 2: FWHM }=4.2 \text { pixels; MTF at Nyquist }=0.004 \\
\text { Band 3: FWHM }=4.2 \text { pixels; } \text { MTF at Nyquist }=0.007 \\
\text { Band 4: FWHM }=4.3 \text { pixels; } \text { MTF at Nyquist }=0.009\end{array}$ \\
\hline
\end{tabular}




\section{Analysis}

Analysis of the datasets consists of analyzing the geometric quality of data (geolocation), the radiometric quality of data (measuring the linearity of the sensor against Sentinel), and the spatial performance, which measures the resolvability of objects within the image.

\section{Geometric Performance}

The geometric performance of the sensor is analyzed in two stages. In the first stage, the registration quality of bands of the data against each other are measured and quantified. In the second stage, the geolocation of the product is validated by comparing against a dataset of higher accuracy.

\section{Interior (Band to Band)}

For this analysis, each band of the SkySat image was registered against all other bands using the Landsat Image Assessment System software to obtain the results. Results from one image were gathered to determine the mean error and root mean square error as listed in table 4 with results represented in pixels at a $0.81-\mathrm{m}$ GSD. Greater misalignment was seen with band 4 (NIR), likely as a result of its spectral distinctness from bands 1-3. A graphical representation of the analysis results for band 1 when compared with each of the other bands is shown in figures 2, 3, and 4. Together, the interior and exterior geometric analysis results, as reported in the "Interior (Band to Band)" and "Exterior (Geometric Location Accuracy)" sections, provide a comprehensive assessment of geometric accuracy.

\section{Exterior (Geometric Location Accuracy)}

For this analysis, the ground reference dataset was chosen to be photograph-identifiable surveyed GCPs collected using differential global positioning system-based measurements. These measurements were obtained in July-August 2019, in and around the city of Sioux Falls, South Dakota. The GSD of SkySat data makes the GCPs identifiable within the imagery. The accuracy of the reference global positioning system-based measurements was precise (less than 3 centimeters horizontally at $1 \sigma$, where $\sigma$ is the standard deviation of the measurements recorded by the Global Navigation Satellite System receiver). The mean error and root mean square error results are listed in table 5, and results are represented in pixels at a 0.81-m GSD.

A graphical representation of the geometric analysis is shown in figure 5. Within this figure, red dots indicate available GCPs and green dots indicate the GCPs used for measurement. Some GCPs were not checked because they could not be properly identified on the SkySat image because of issues such as obstruction.

Table 4. Band-to-band registration error (in pixels) for reference bands 1, 2, 3, and 4.

[RMSE, root mean square error]

\begin{tabular}{|c|c|c|c|c|}
\hline Band & $\begin{array}{l}\text { Mean error } \\
\text { (easting) }\end{array}$ & $\begin{array}{c}\text { Mean error } \\
\text { (northing) }\end{array}$ & $\begin{array}{c}\text { RMSE } \\
\text { (easting) }\end{array}$ & $\begin{array}{c}\text { RMSE } \\
\text { (northing) }\end{array}$ \\
\hline \multicolumn{5}{|c|}{ Reference-Band 1} \\
\hline Band 2 & 0.11 & 0.00 & 0.23 & 0.19 \\
\hline Band 3 & 0.29 & -0.04 & 0.42 & 0.24 \\
\hline Band 4 & 0.32 & 0.00 & 0.97 & 0.68 \\
\hline \multicolumn{5}{|c|}{ Reference-Band 2} \\
\hline Band 1 & -0.11 & 0.00 & 0.25 & 0.20 \\
\hline Band 3 & 0.18 & -0.03 & 0.28 & 0.17 \\
\hline Band 4 & 0.21 & -0.01 & 0.87 & 0.63 \\
\hline \multicolumn{5}{|c|}{ Reference-Band 3} \\
\hline Band 1 & -0.29 & 0.04 & 0.44 & 0.26 \\
\hline Band 2 & -0.18 & 0.03 & 0.28 & 0.17 \\
\hline Band 4 & 0.01 & 0.06 & 0.89 & 0.67 \\
\hline \multicolumn{5}{|c|}{ Reference-Band 4} \\
\hline Band 1 & -0.27 & 0.01 & 0.99 & 0.73 \\
\hline Band 2 & -0.20 & 0.01 & 0.88 & 0.65 \\
\hline Band 3 & 0.00 & -0.05 & 0.91 & 0.67 \\
\hline
\end{tabular}




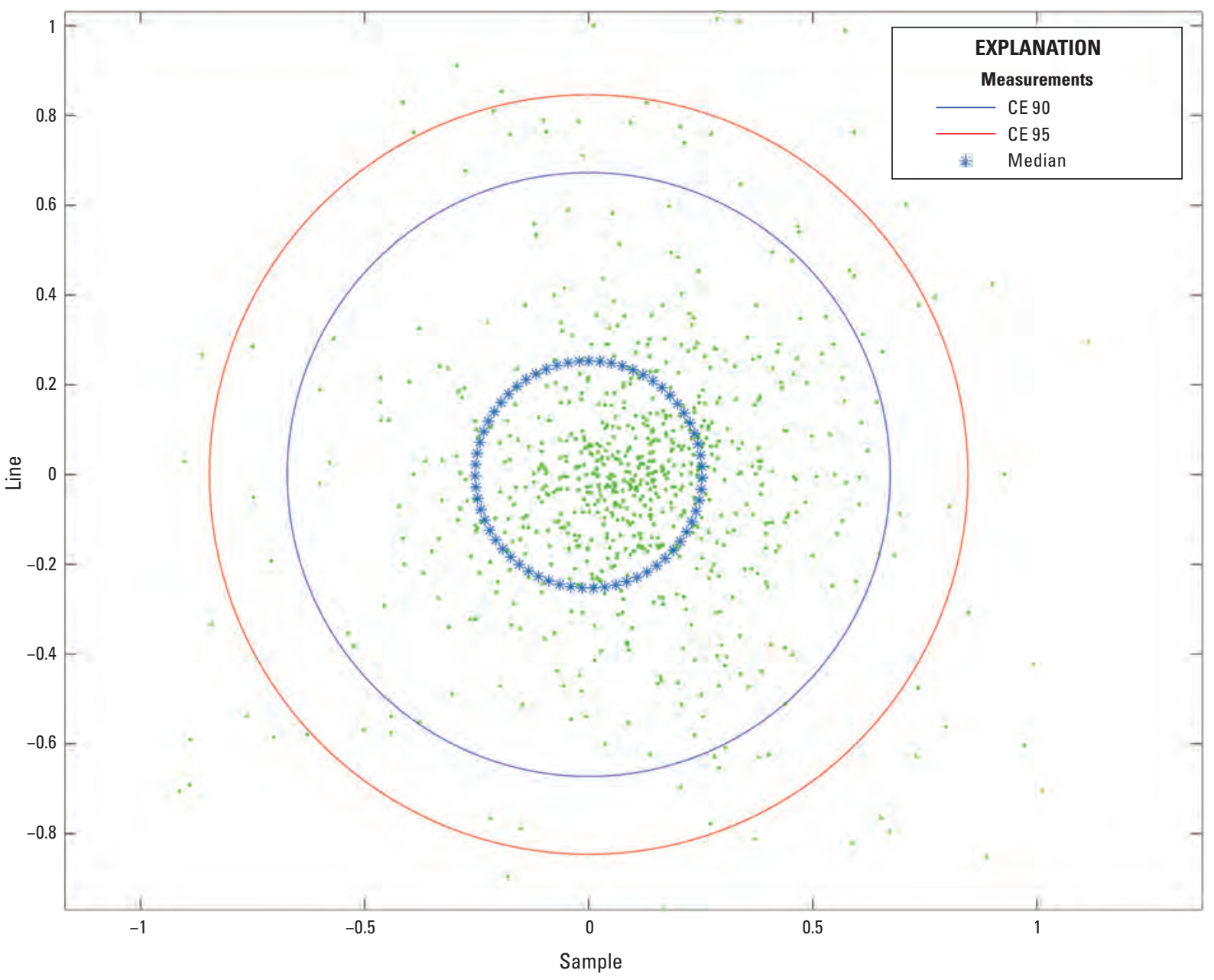

Figure 2. Band 1 (blue) to band 2 (green) band-to-band results. CE 90 and CE 95 represent the radius of the circle such that there is a 90-percent and a 95-percent probability that the error lies within the circle, respectively. 


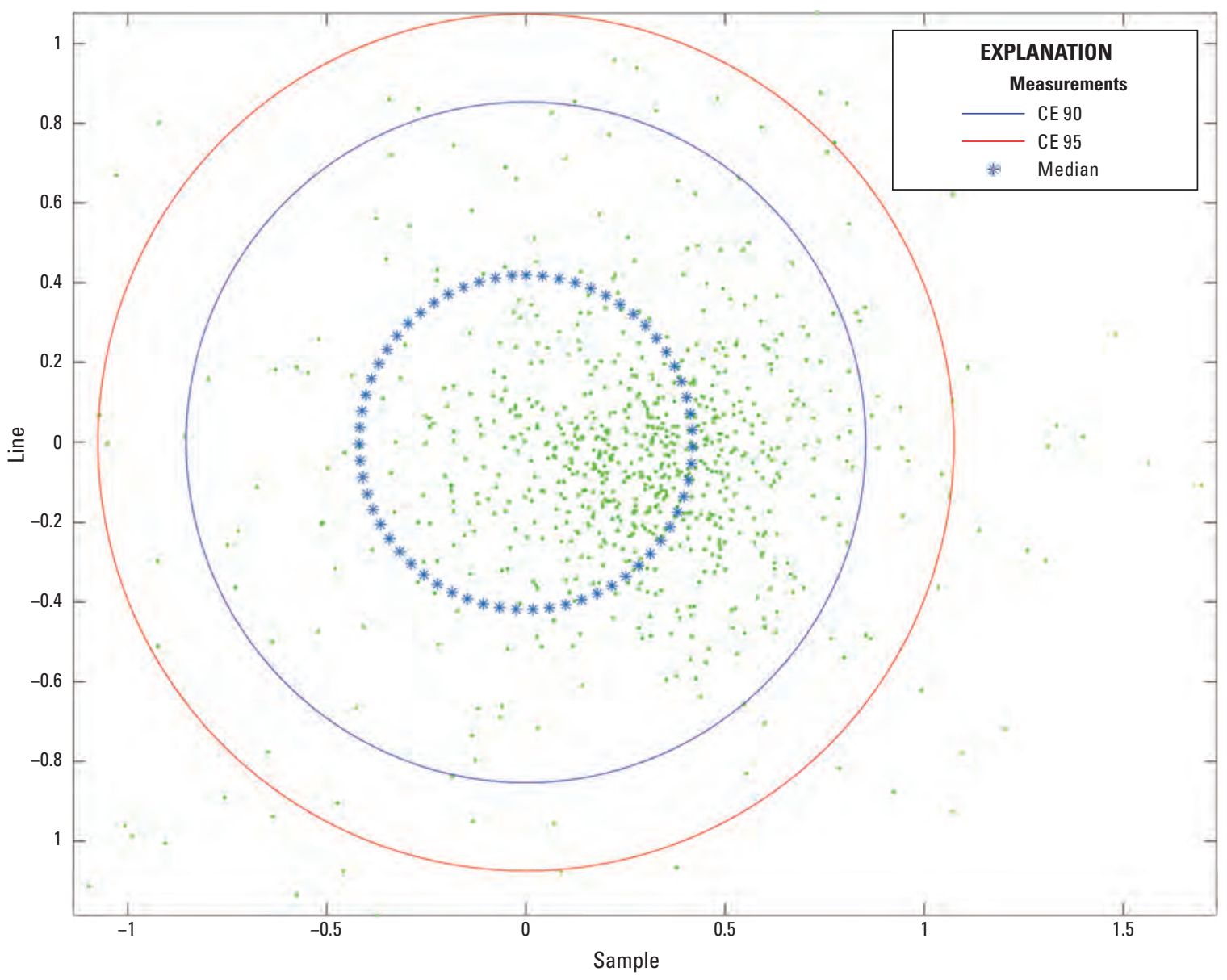

Figure 3. Band 1 (blue) to band 3 (red) band-to-band results. CE 90 and CE 95 represent the radius of the circle such that there is a 90-percent and a 95-percent probability that the error lies within the circle, respectively. 


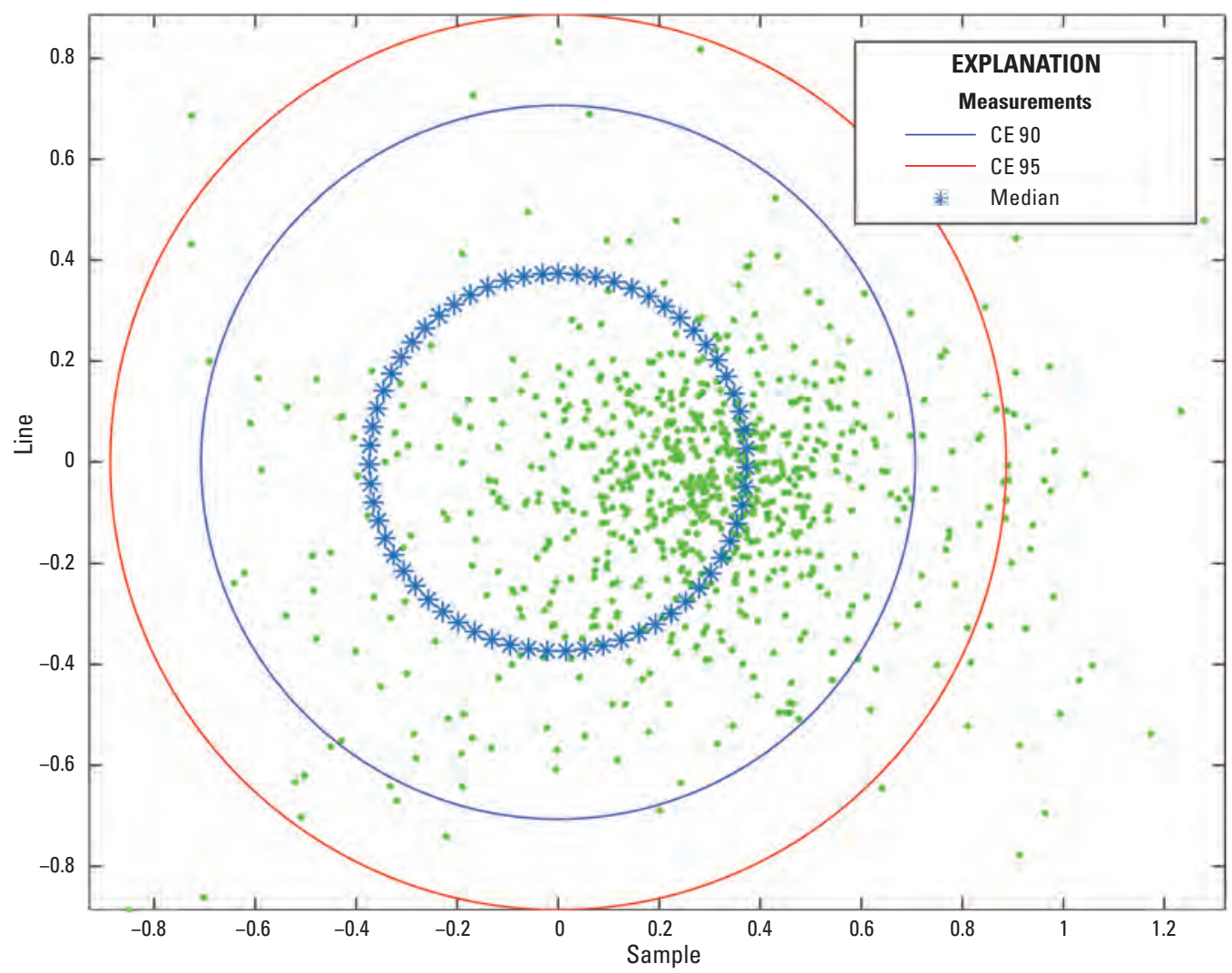

Figure 4. Band 1 (blue) to band 4 (near infrared) band-to-band results. CE 90 and CE 95 represent the radius of the circle such that there is a 90 -percent and a 95-percent probability that the error lies within the circle, respectively.

Table 5. Geometric error relative to ground control points.

[ID, identifier; RMSE, root mean square error; $m$, meter]

\begin{tabular}{ccccc}
\hline Scene ID & $\begin{array}{c}\text { Mean error } \\
\text { (easting) }\end{array}$ & $\begin{array}{c}\text { Mean error } \\
\text { (northing) }\end{array}$ & $\begin{array}{c}\text { RMSE } \\
\text { (easting) }\end{array}$ & $\begin{array}{c}\text { RMSE } \\
\text { (northing) }\end{array}$ \\
\hline 20200603_170743_ssc4_u0001 & 0.41 pixel & 0.20 pixel & 0.79 pixel & 0.59 pixel \\
& $(0.33 \mathrm{~m})$ & $(0.16 \mathrm{~m})$ & $(0.64 \mathrm{~m})$ & $(0.48 \mathrm{~m})$ \\
\hline
\end{tabular}




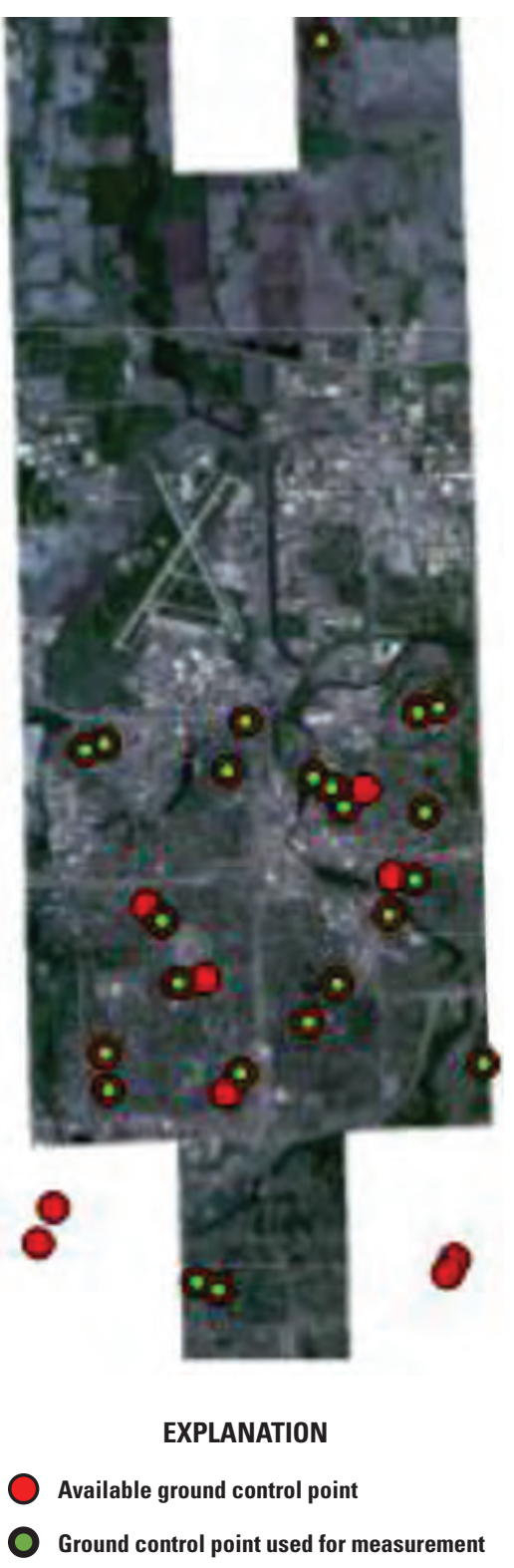

Figure 5. Geometric error for image (scene identifier 20200603_170743 ssc4_u0001) compared to ground control points. 


\section{Radiometric Performance Evaluation}

For this analysis, cloud-free regions of interest were selected within a SkySat image and cross comparisons were completed with Sentinel-2 as the reference sensor. Once the relative georeferencing error between the Sentinel-2 Multispectral Imager and SkySat has been corrected, Top of Atmosphere reflectance values from the two sensors are extracted. The scatterplots (figs. 6-9) are drawn in a way that the $\mathrm{x}$-axis is the reference sensor and the $y$-axis is the comparison sensor. The linear regression, thus, represents Top of Atmosphere reflectance relative to that of the reference sensor.
Ideally, the slope should be near unity and the offset should be near zero. For instance, if the slope is greater than unity, that means the comparison sensor has a tendency to overestimate Top of Atmosphere reflectance compared to the reference sensor.

A statistical representation of the linear regression differences between the sensor pair is listed in table 6, and graphical representations of the linear regression analysis results are shown in figures 6-9. Within the graphs, the $\mathrm{x}$-axis represents the Top of Atmosphere reflectance values from Sentinel-2, whereas the y-axis represents data from SkySat.

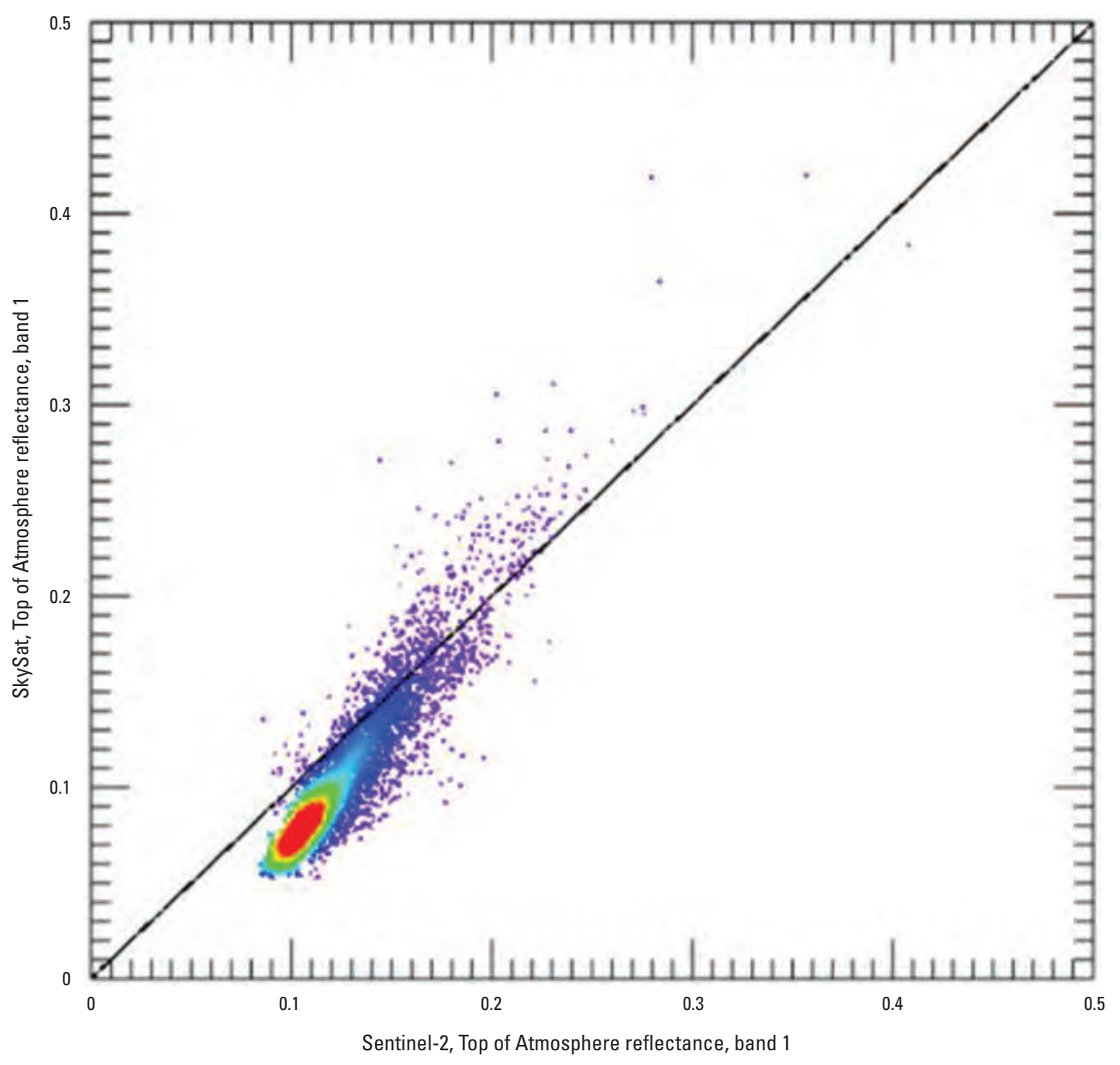

Figure 6. Top of Atmosphere reflectance comparison for Sentinel-2 and Planet's SkySat band 1 (blue). 


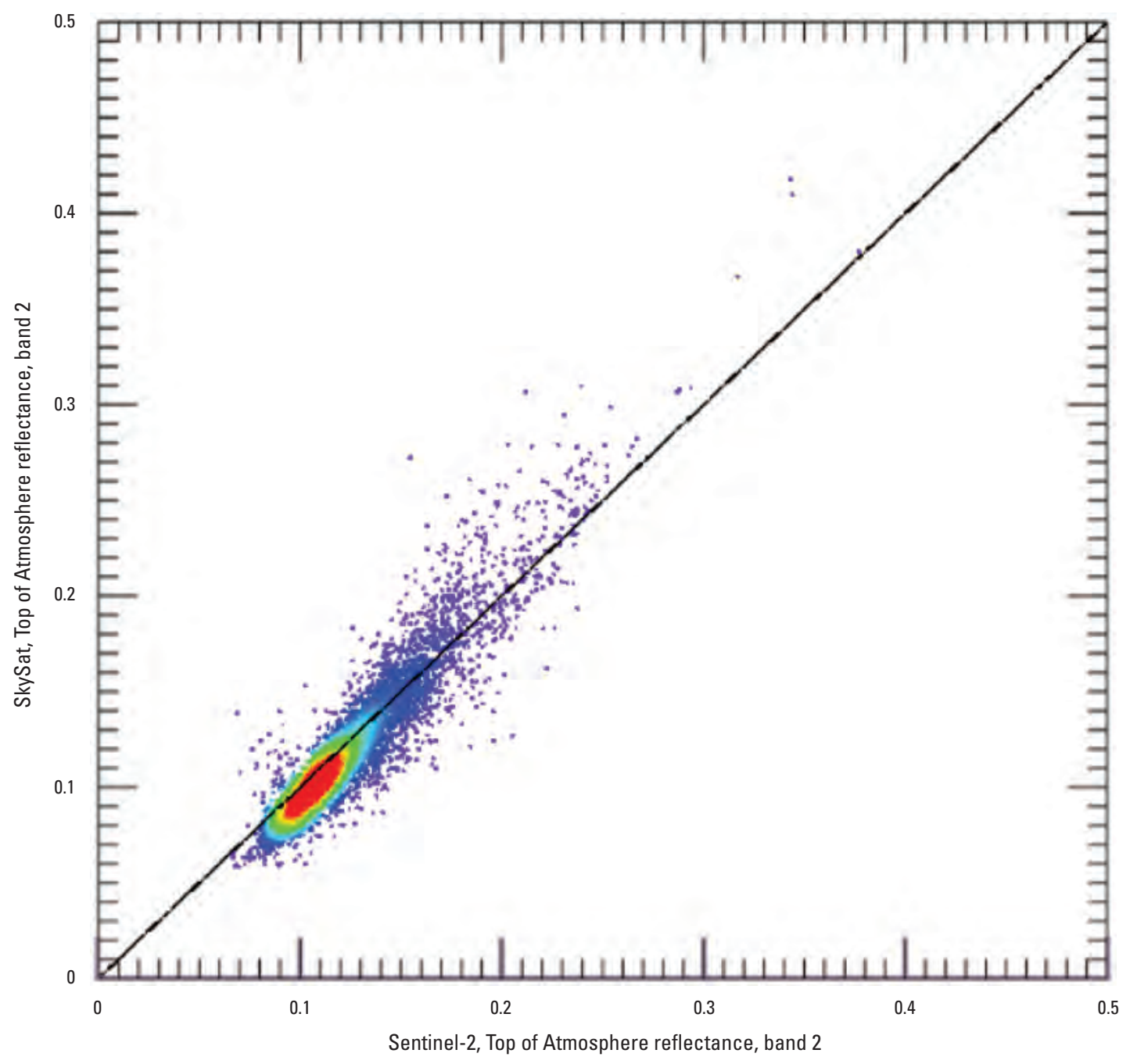

Figure 7. Top of Atmosphere reflectance comparison for Sentinel-2 and Planet's SkySat band 2 (green). 


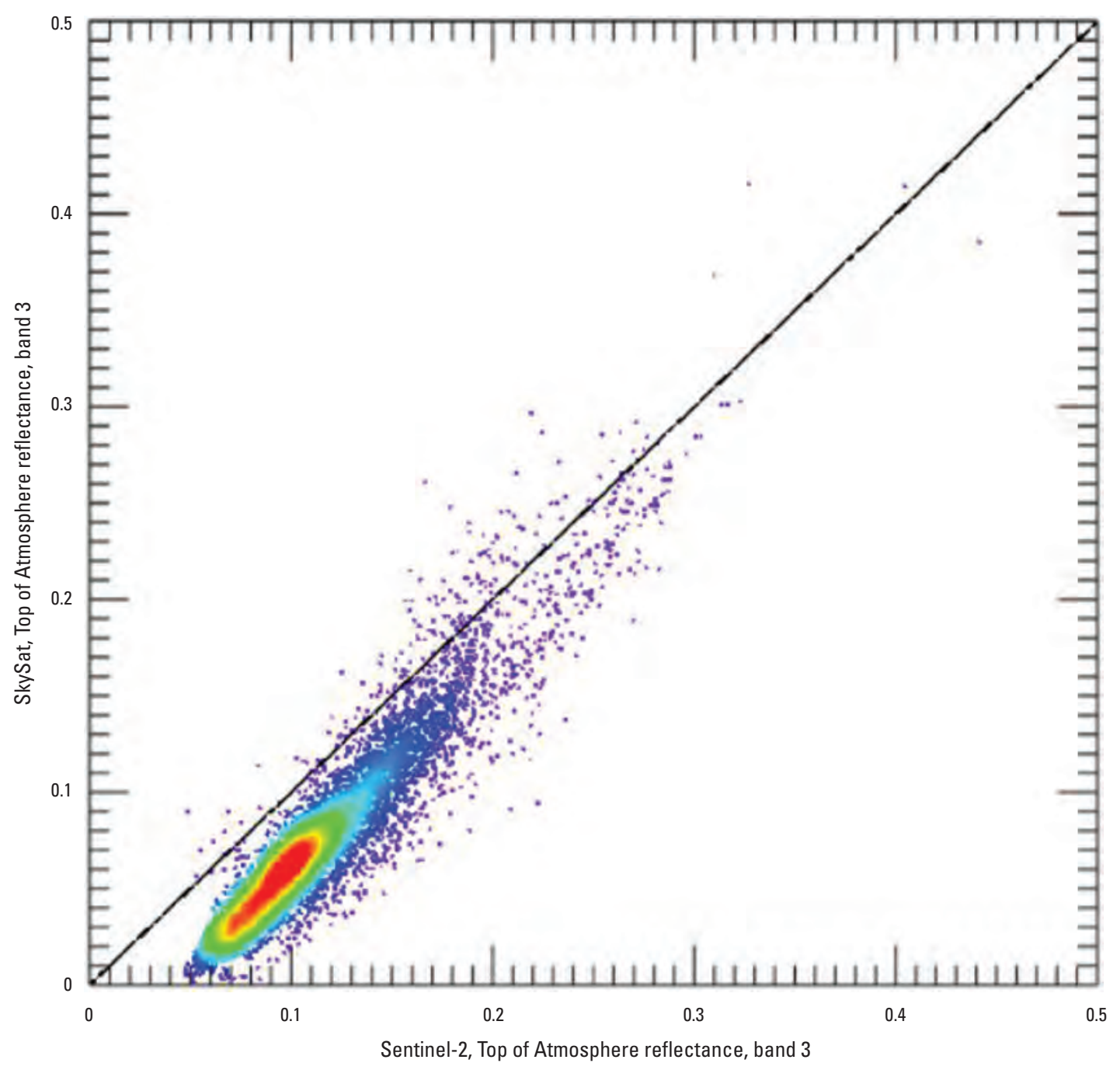

Figure 8. Top of Atmosphere reflectance comparison for Sentinel-2 and Planet's SkySat band 3 (red). 


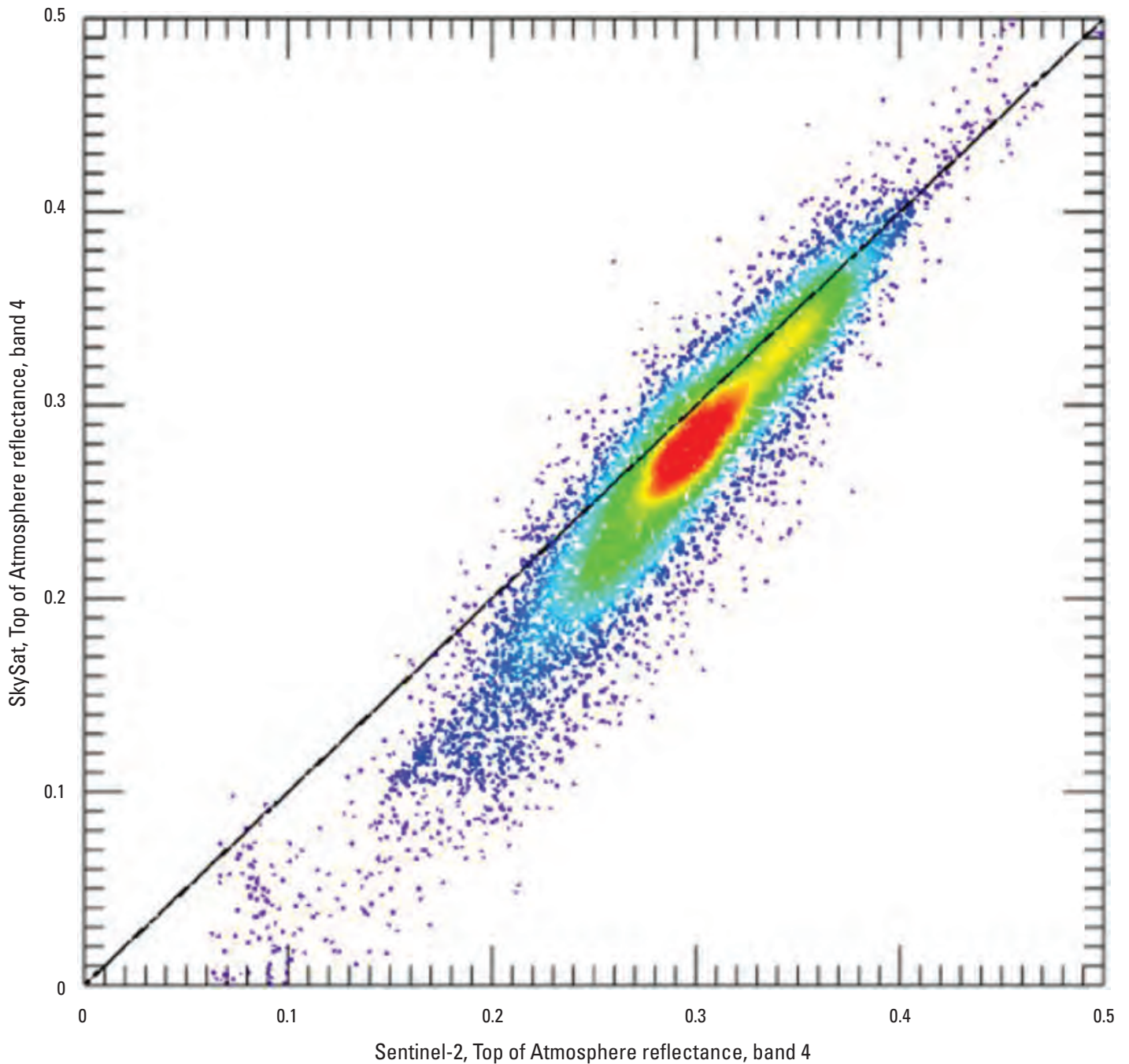

Figure 9. Top of Atmosphere reflectance comparison for Sentinel-2 and Planet's SkySat band 4 (near infrared).

Table 6. Top of Atmosphere reflectance comparison against Sentinel-2.

[The scene identifier for this dataset is 20200617_171457_ssc12d1_0017; NIR, near infrared; \%, percent; $R^{2}$, coefficient of determination]

\begin{tabular}{lcccc}
\hline \multicolumn{1}{c}{ Statistics } & Band 1-Blue & Band 2-Green & Band 3-Red & Band 4-NIR \\
\hline Uncertainty (\%) & 10.65 & 9.16 & 12.72 & 9.75 \\
$R^{2}$ & 0.855 & 0.867 & 0.881 & 0.837 \\
Radical offset & 0.056 & 0.033 & 0.052 & 0.113 \\
Radical slope & 0.644 & 0.754 & 0.797 & 0.670 \\
\hline
\end{tabular}

\section{Spatial Performance Evaluation}

For this analysis, a SkySat image (scene identifier 20200617_171457_ssc12d1_0017) over the Baotou, China, spatial test range was downloaded from the Planet server. This spatial test range contains many standard targets, which allow for easy evaluation of all measures of spatial data quality, including full width at half maximum and a modulation transfer function at Nyquist frequency, as listed in table 7. An example of SkySat data over the Baotou test site is shown in figure 10 . 
Table 7. Spatial performance of Planet's SkySat.

[FWHM, full width at half maximum; MTF, modulation transfer function; NIR, near infrared]

\begin{tabular}{|c|c|c|}
\hline Spatial analysis & FWHM & MTF at Nyquist \\
\hline Band 1-blue & 3.7 pixels & 0.009 \\
\hline Band 2-green & 4.2 pixels & 0.004 \\
\hline Band 4 -NIR & 4.3 pixels & 0.009 \\
\hline
\end{tabular}

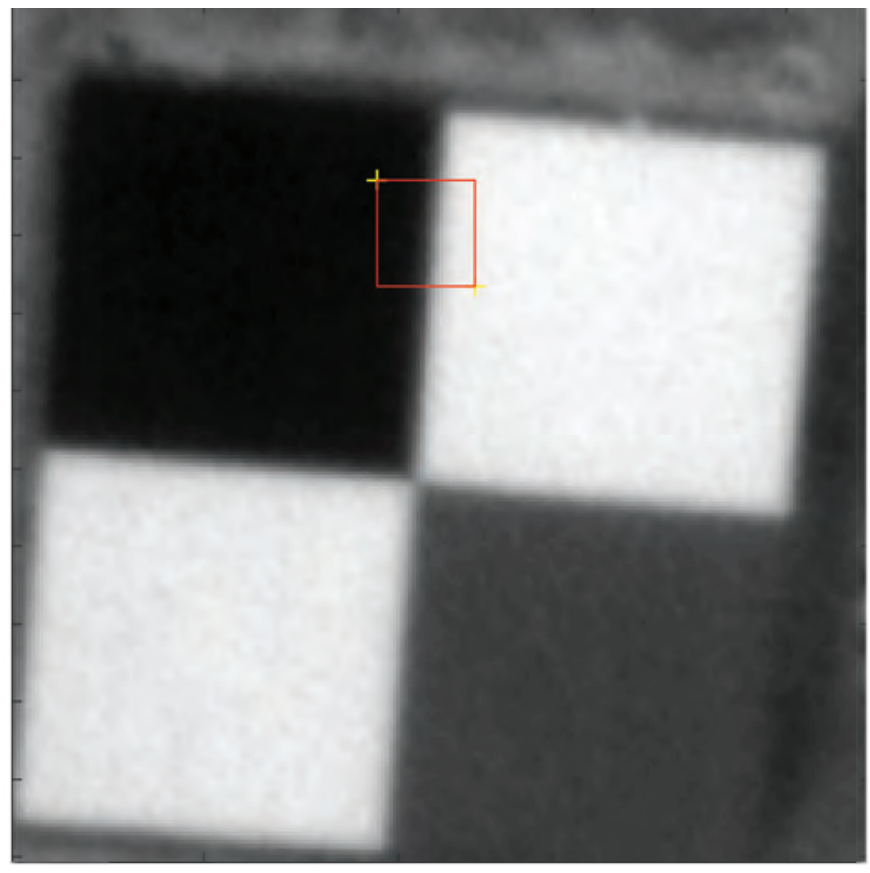

\section{EXPLANATION}

Grid showing the edge transect region of interest

Figure 10. Planet's SkySat data over the Baotou, China, test site.

The band 1 (blue) edge spread and line spread function results are shown in figure 11, the results for band 2 (green) are shown in figure 12, the results for band 3 (red) are shown in figure 13, and the results for band 4 (NIR) are shown in figure 14. 

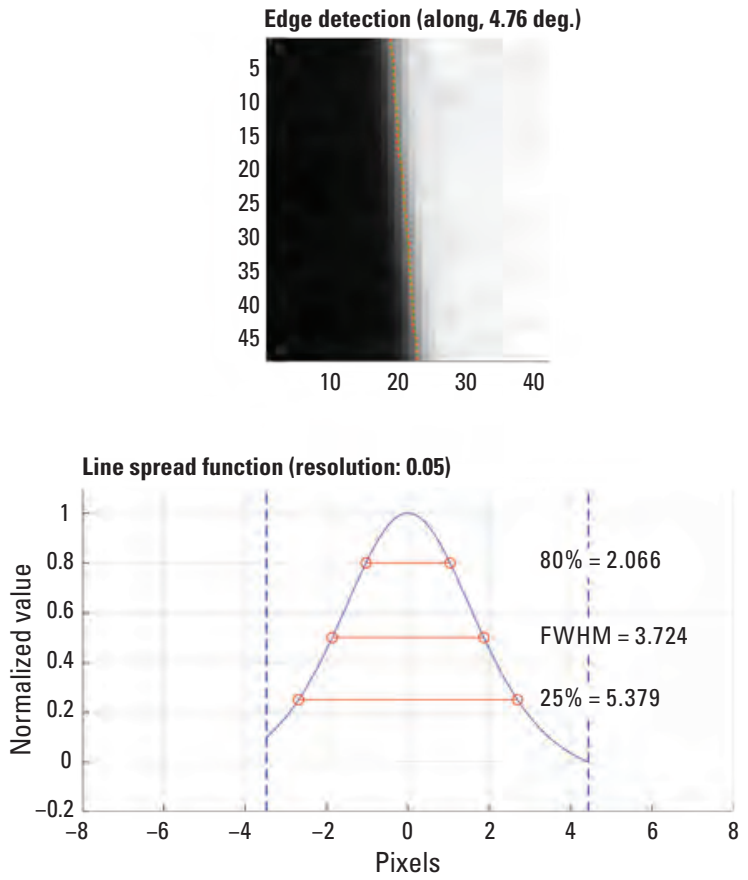
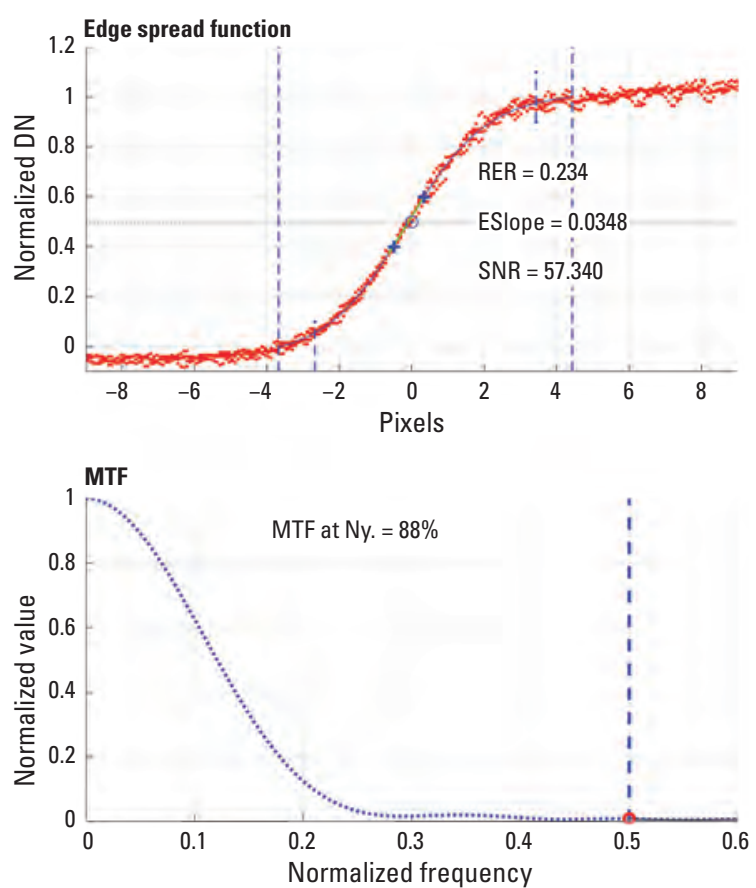

Figure 11. Band 1 (blue) edge spread and line spread function (upper) and full width at half maximum (FWHM) and modulation transfer function (MTF; lower) curves. [deg., degree; DN, digital number; RER, relative edge response; ESlope, slope of edge; SNR, signal-to-noise ratio; \%, percent; Ny., Nyquist]
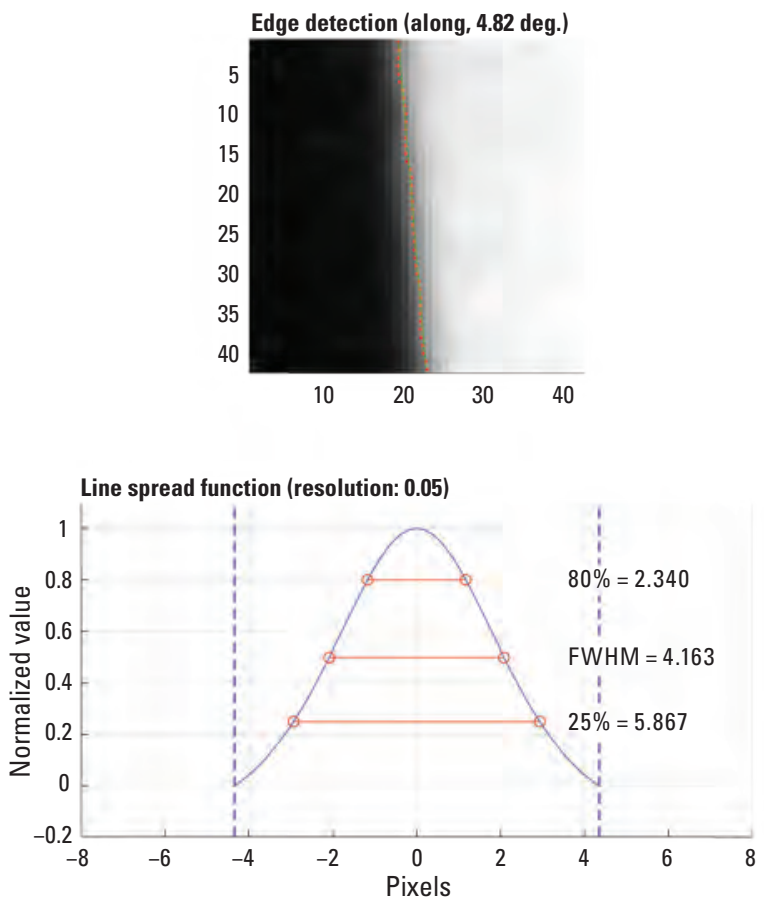
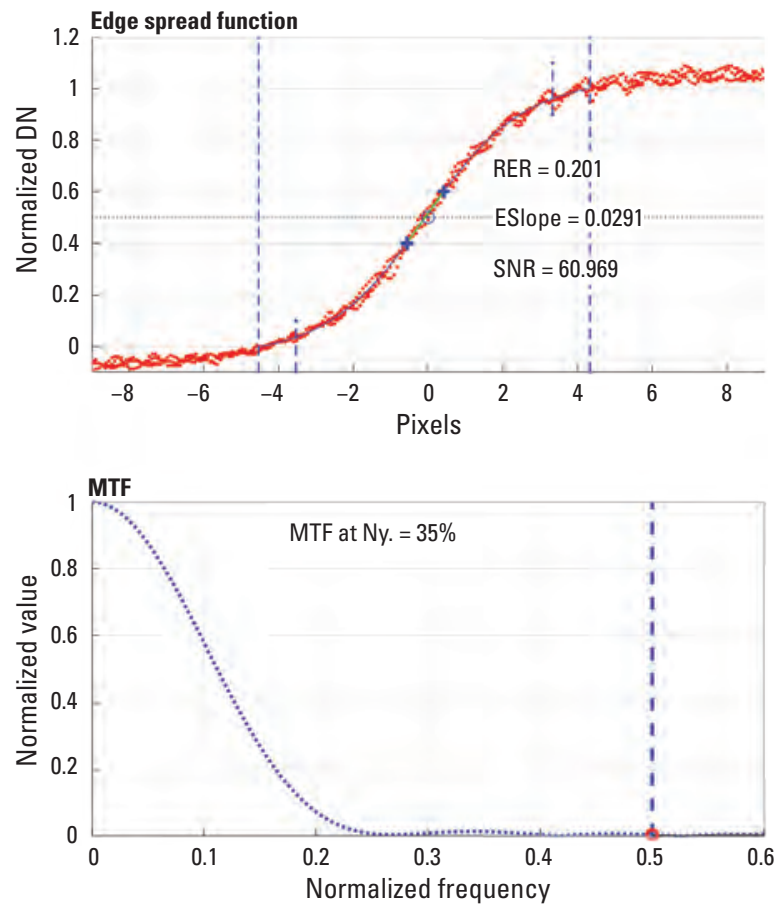

Figure 12. Band 2 (green) edge spread and line spread function (upper) and full width at half maximum (FWHM) and modulation transfer function (MTF; lower) curves. [deg., degree; DN, digital number; RER, relative edge response; ESlope, slope of edge; SNR, signal-to-noise ratio; \%, percent; Ny., Nyquist] 

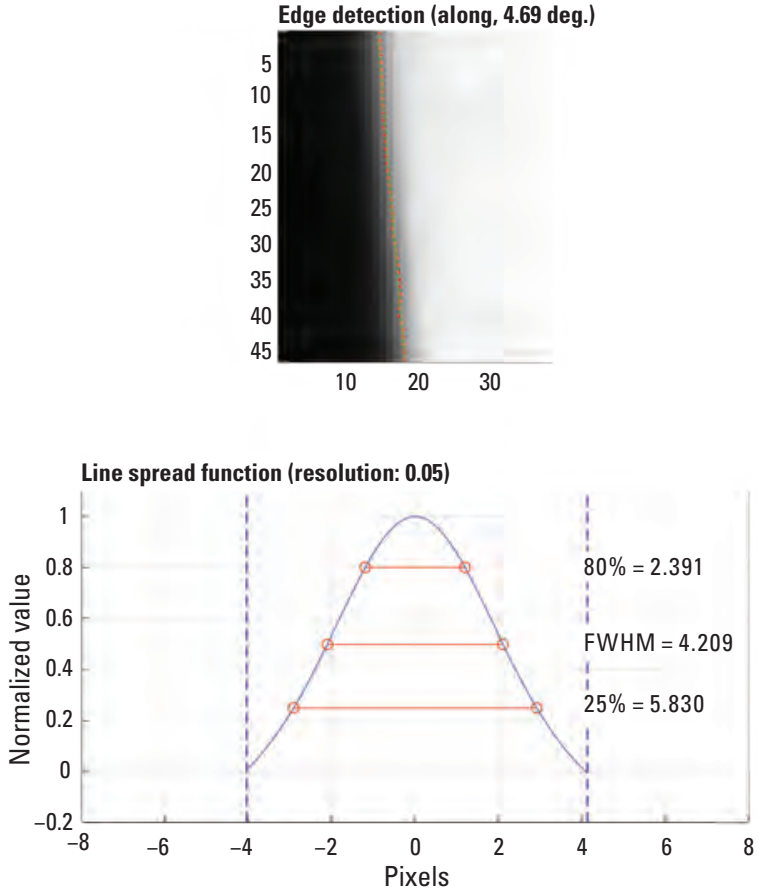
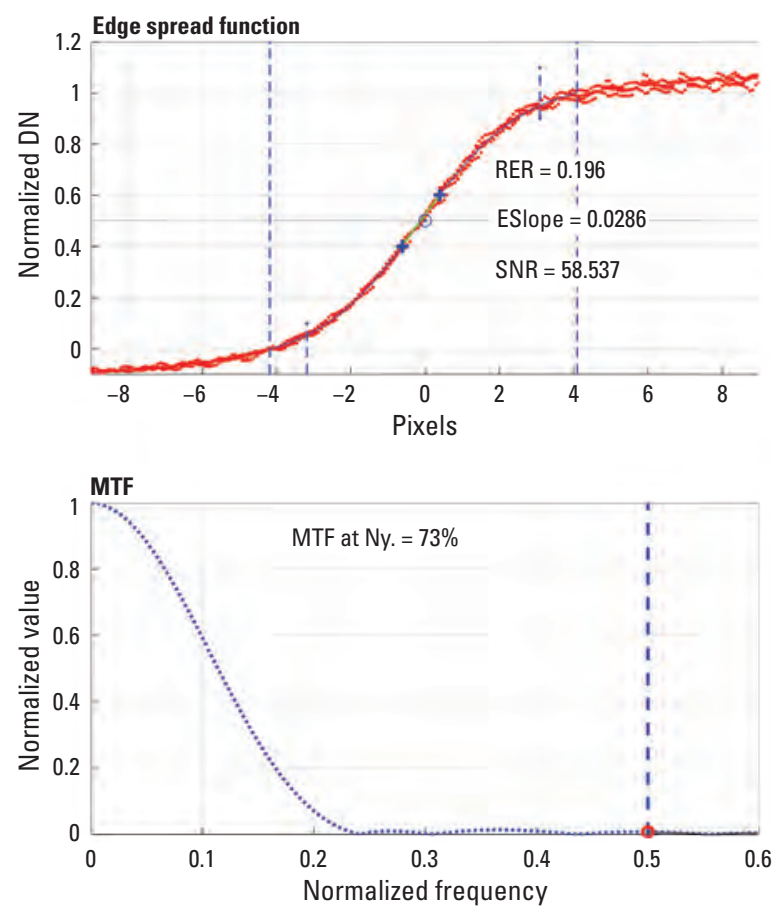

Figure 13. Band 3 (red) edge spread and line spread function (upper) and full width at half maximum (FWHM) and modulation transfer function (MTF; lower) curves. [deg., degree; DN, digital number; RER, relative edge response; ESlope, slope of edge; SNR, signal-to-noise ratio; \%, percent; Ny., Nyquist]
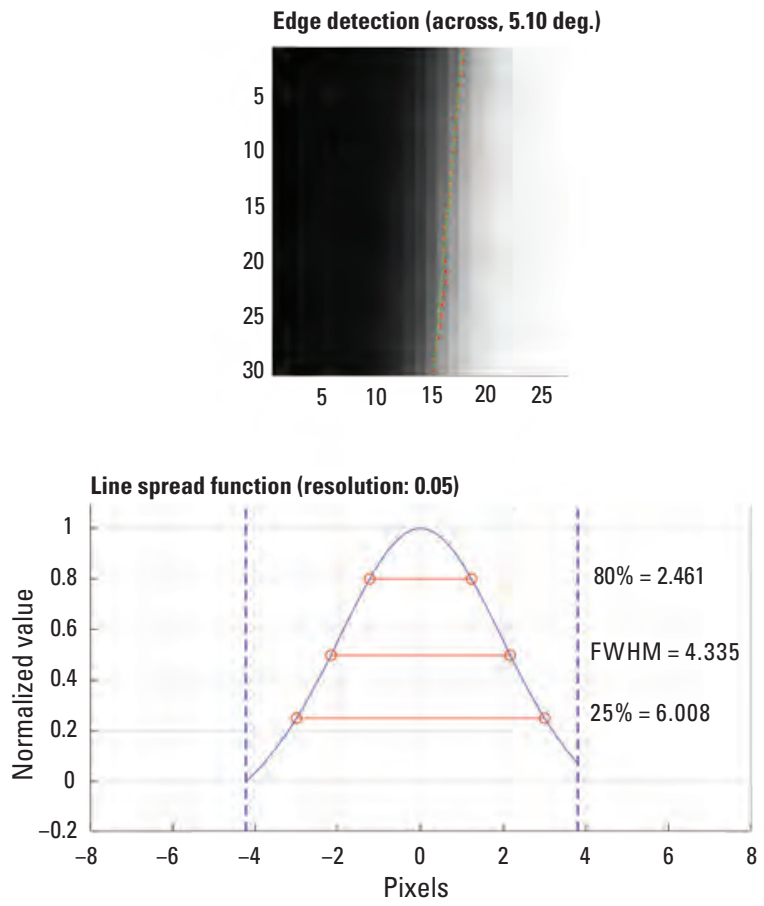
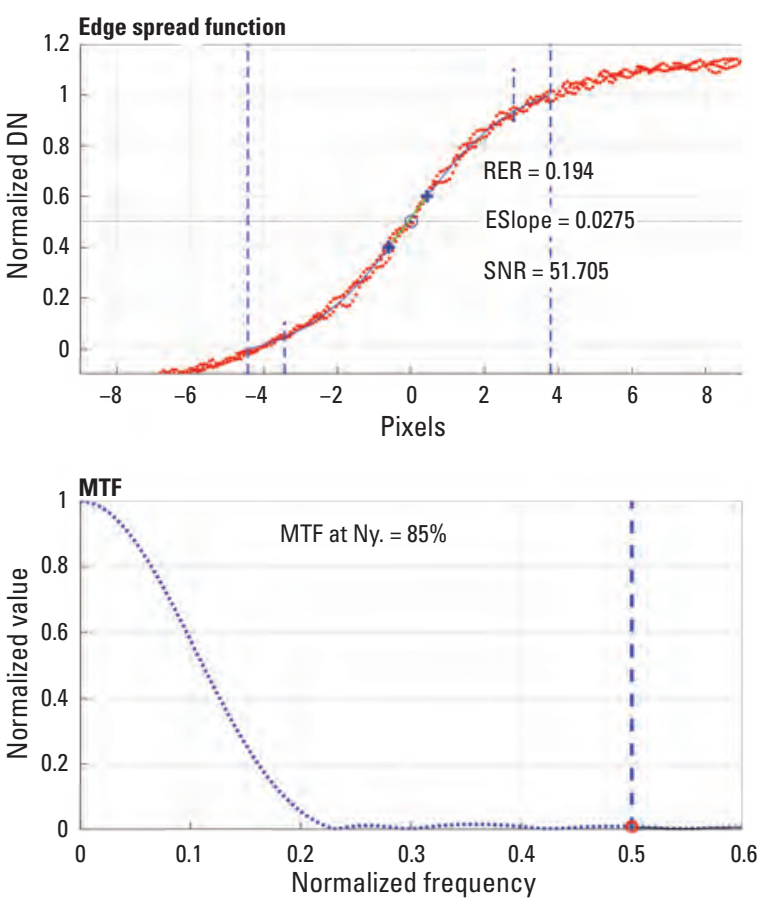

Figure 14. Band 4 (near infrared) edge spread and line spread function (upper) and full width at half maximum (FWHM) and modulation transfer function (MTF; lower) curves. [deg., degree; DN, digital number; RER, relative edge response; ESlope, slope of edge; SNR, signal-to-noise ratio; \%, percent; Ny., Nyquist] 


\section{Summary and Conclusions}

This report summarizes the sensor performance of Planet's SkySat system based on the U.S. Geological Survey Earth Resources Observation and Science Cal/Val Center of Excellence system characterization process. In summary, we have determined that this sensor provides an interior geometric performance of a 0.38 - $(0.47$ pixel) to 0.75 -meter ( $\mathrm{m}$; 0.93 pixel) root mean square error in easting and a 0.27 - (0.33 pixel) to $0.55-\mathrm{m}$ ( 0.68 pixel) root mean square error in northing, an exterior geometric performance of 0.26 (0.32 pixel) to $1.04 \mathrm{~m}$ (1.28 pixels), a radiometric performance of 0.033 to 0.797 (offset and slope), and a spatial performance of 3.7 to 4.3 pixels at full width at half maximum, with a modulation transfer function at a Nyquist frequency of 0.004 to 0.009 .

In conclusion, we have completed an Earth Resources Observation and Science Cal/Val Center of Excellence standardized system characterization of the SkySat sensing system. Although we follow characterization procedures that are standardized across the many sensors and sensing systems under evaluation, these procedures are customized to fit the individual sensor as was done with SkySat. The team has acquired the data, defined proper testing methodologies, carried out comparative tests against specific references, recorded measurements, completed data analyses, and quantified sensor performance accordingly. The team also endeavored to retain all data, measurements, and methods. This is key to ensure that all data and measurements are archived and accessible and that the performance results are reproducible.

\section{Selected References}

Planet Labs, Inc., 2021, Planet: Planet Labs, Inc., web page, accessed July 18, 2021, at https://www.planet.com/.

Ramaseri Chandra, S.N., Christopherson, J.B., and Casey, K.A., 2020, 2020 Joint Agency Commercial Imagery Evaluation-Remote sensing satellite compendium: U.S. Geological Survey Circular 1468 (ver. 1.1, October 2020), 253 p. [Also available at https://doi.org/10.3133/cir1468.] [Supersedes USGS Circular 1455.]

U.S. Geological Survey, 2020a, EROS CalVal Center of Excellence (ECCOE): U.S. Geological Survey web page, accessed July 18, 2021, at https://www.usgs.gov/corescience-systems/eros/calval.

U.S. Geological Survey, 2020b, EROS CalVal Center of Excellence (ECCOE) —JACIE: U.S. Geological Survey web page, accessed July 18, 2021, at https://www.usgs.gov/ core-science-systems/eros/calval/jacie?qt-science_support page_related_con $=3 \# q \mathrm{qt}-\mathrm{science}$ _support_page_related_con.

U.S. Geological Survey, 2020c, Landsat missions - Glossary and acronyms: U.S. Geological Survey web page, accessed July 18, 2021, at https://www.usgs.gov/core-sciencesystems/nli/landsat/glossary-and-acronyms. 

For more information about this publication, contact: Director, USGS Earth Resources Observation and Science Center 47914 252nd Street

Sioux Falls, SD 57198

605-594-6151

For additional information, visit: https://www.usgs.gov/centers/eros

Publishing support provided by the

Rolla Publishing Service Center 


\section{$\frac{1}{8}$}

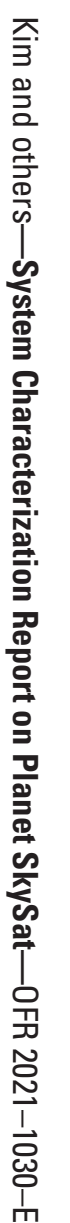

